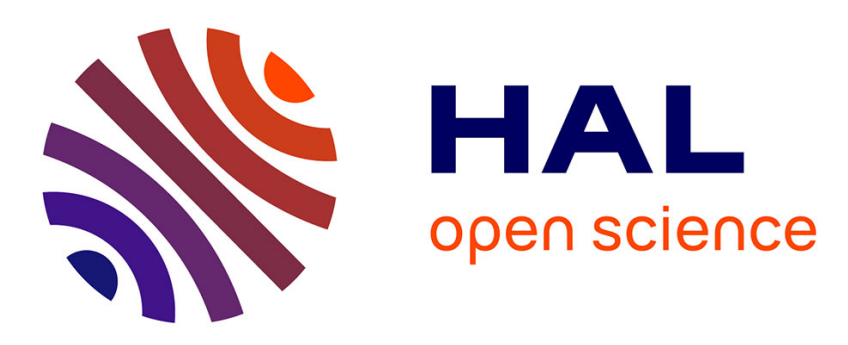

\title{
Body mass index trajectories and functional decline in older adults: Three-City Dijon cohort study
}

Fanny Artaud, Archana Singh-Manoux, Aline Dugravot, Béatrice Tavernier, Christophe Tzourio, Alexis Elbaz

\section{- To cite this version:}

Fanny Artaud, Archana Singh-Manoux, Aline Dugravot, Béatrice Tavernier, Christophe Tzourio, et al. Body mass index trajectories and functional decline in older adults: Three-City Dijon cohort study. European Journal of Epidemiology, 2015, pp.1-11. 10.1007/s10654-015-0027-4 . inserm-01147251

\section{HAL Id: inserm-01147251 https://www.hal.inserm.fr/inserm-01147251}

Submitted on 30 Apr 2015

HAL is a multi-disciplinary open access archive for the deposit and dissemination of scientific research documents, whether they are published or not. The documents may come from teaching and research institutions in France or abroad, or from public or private research centers.
L'archive ouverte pluridisciplinaire HAL, est destinée au dépôt et à la diffusion de documents scientifiques de niveau recherche, publiés ou non, émanant des établissements d'enseignement et de recherche français ou étrangers, des laboratoires publics ou privés. 


\section{Body mass index trajectories and functional decline in older adults: Three- City Dijon cohort study}

Fanny Artaud; Archana Singh-Manoux; Aline Dugravot; Béatrice Tavernier; Christophe Tzourio; Alexis Elbaz.

INSERM, Centre for research in Epidemiology and Population Health, U1018, Epidemiology of aging and age related diseases, F-94807, Villejuif, France (FA, ASM, AD, AE); Univ de Versailles St-Quentin, UMRS 1018, F-78035, Versailles, France (FA, ASM, AD, AE); Department of Epidemiology and Public Health, University College London, UK (ASM); CHU Dijon, Department of Geriatrics, Dijon, France (BT); INSERM U897, Neuroepidemiology team, Bordeaux, France (CT); University of Bordeaux, Bordeaux, France (CT).

Corresponding Author: Alexis Elbaz, INSERM, U1018, CESP Centre for Research in Epidemiology and Population Health, F-94807, Villejuif, France. Telephone number: 33 (0) 1 455953 70. Fax number: 33 (0) 1777474 03. E-mail: alexis.elbaz@inserm.fr

Abstract: 230 words

Body: 3,498 words

3 Tables, 1 Figure, 54 references

Supplementary data: supplementary methods, 7 supplementary tables 


\section{ABSTRACT}

Obesity, whose prevalence is increasing, is associated with poor functional status at older ages. However, much of this evidence is cross-sectional with little known about longitudinal associations. We examined associations of body mass index (BMI), and change in BMI, with change in objective (walking speed, WS) and self-reported (disability) measures of motor decline. Analyses included participants (65-85 years) from the Dijon center of the Three-City study (France) with up to five WS $(\mathrm{N}=4,007)$ and six disability assessments $(\mathrm{N}=4,478)$ over 11 years. Data were analyzed using regression models for repeated measures. Mean baseline WS was $153 \mathrm{~cm} / \mathrm{s}$. Compared to normal weight persons, obese participants at baseline walked slower and reported more disability; they also experienced $45 \%$ faster WS decline (-18.63 $\mathrm{cm} / \mathrm{s} / 10$ years $v s .-12.85 \mathrm{~cm} / \mathrm{s} / 10 y e a r s, P=0.002)$. Participants who lost or gained weight had $47 \%(-18.85 \mathrm{~cm} / \mathrm{s} / 10 y e a r s, P<0.001)$ and $33 \%(-17.08 \mathrm{~cm} / \mathrm{s} / 10$ years, $P=0.002)$ respectively greater WS decline than participants in the normal BMI change category. $24 \%$ of participants reported disability at least once during the follow-up, those who lost or gained weight had a 1.63 and 1.34 respectively higher odds of disability than participants in the normal BMI change category $(P=0.001)$. Associations remained after adjustment for covariates. In conclusion, obesity is associated with worse motor performances, a higher risk of disability, and faster motor decline. Our results underline the interest of repeated BMI and motor assessments to identify those at higher risk of disability.

Keywords: aged, body mass index, cohort study, disability, epidemiology, motor decline. 


\section{INTRODUCTION}

Motor function declines progressively across the adult lifespan with marked inter-individual heterogeneity as a result of aging and disease [1]. Poor motor performance in older adults is associated with adverse health events, such as disability and death [2, 3]. Understanding determinants of motor decline may allow the identification of high risk populations to develop preventive measures. The increasing burden of disability due to demographic changes makes this objective particularly salient.

Many countries are confronted with an obesity epidemic [4]. In France, the prevalence of obesity in those 65 years and older increased from $11.2 \%$ in 1997 to $18.7 \%$ in 2012 , more markedly in this age group than in younger persons [5]. Obesity is associated with the risk of disability [6-9] and worse motor performances when these are assessed once [10-13], but the results from studies about the association between obesity and subsequent motor decline remain inconclusive [12, 14-16]. Moreover, weight change is associated with the risk of disability $[6-8,14]$ but few studies have examined the association between weight change and either motor performances assessed once $[13,14]$ or motor decline over time $[15,16]$. Accordingly, our objective was to examine the association of BMI and change in BMI over time with two measures of motor function: incident self-reported disability and change in clinically assessed walking speed (WS) over an 11-year follow-up. We hypothesized that both high BMI and gain in weight over time would be associated with incident disability and more pronounced decline in WS. 


\section{METHODS}

\section{Study population}

The Three City (3C) prospective cohort study recruited community-dwelling older subjects $\geq 65$ years from electoral rolls in three French cities [17]. The present study is based on data from Dijon $(n=4,931)$ where we undertook a study on motor performance. Participants $\leq 85$ years were invited to the study center at baseline (1999-2001) and after two (wave 1/200102), four (wave 2/2003-04), seven (wave 4/2006-07), nine (wave 5/2008-09), and 11 years (wave 6/2010-12). Older participants were seen at home. From wave 2 onwards, all participants were offered the opportunity of being seen at home. Wave 3 (2005-06) consisted of a self-administered questionnaire.

The study protocol was approved by the ethical committee of the Kremlin-Bicêtre University-Hospital (France); all participants gave written informed consent.

\section{BMI and covariates}

Weight was measured during clinical examinations or self-reported at all waves, height was measured or self-reported at baseline and wave 4. Clinical measures, preferred when available, were obtained for weight for $89 \%$ of participants at baseline, $0 \%$ at waves 1 and 2, $67 \%$ at wave $4,91 \%$ at wave 5 , and $81 \%$ at wave 6 ; these proportions were of $89 \%$ at baseline and $67 \%$ at wave 4 for height. BMI $\left(\mathrm{kg} / \mathrm{m}^{2}\right)$ was calculated as weight divided by height squared; baseline height was used to compute BMI at baseline and waves 1-2, and height from wave 4 for BMI at waves 4-6.

We identified covariates that could mediate the association between BMI and functional decline based on the literature. These include cognitive outcomes, depression, fractures and falls, osteoarthritis, diabetes, dyspnea, cardiovascular disease and hypertension 
which have all been associated with both BMI [18, 19] and motor function [1, 20-22]. Details of covariates assessments are available in supplementary methods. Covariates were assessed at baseline (age, sex, education, marital status) or all waves (cognitive function, depressive symptoms, bone fracture, falls, physical activity, knee or hip replacement for osteoarthritis, diabetes, dyspnea, cardiovascular disease, hypertension, hypercholesterolemia, regular use of non-steroidal anti-inflammatory drug (NSAID) for joint pain, psychotropic drugs).

\section{Walking speed}

WS was measured in participants $\leq 85$ years at the study center at baseline and waves $2,4,5$, and 6 using two photoelectric cells (6 meters apart) connected to a chronometer. Participants were asked to walk at 'usual' and 'fast' (without running) speed. They started walking three meters before the start line. At wave 6 , for participants $\leq 85$ years seen at home, we used portable photoelectric cells (Racetime2 kit light radio, MicroGate ${ }^{\circledR}$ ) to measure WS using the same protocol, over $6 \mathrm{~m}$ in most instances $(85 \%)$ or shorter distances $(3.5-5.9 \mathrm{~m})$ otherwise.

WS (cm/s) was computed as $600 \mathrm{~cm}$ divided by time (seconds). Short-term reproducibility was assessed taking 2 measures 5 minutes apart in a random sample $(n=51)$. Intraclass correlation coefficients (SE) were: usual WS, 0.84 (0.02); fast WS, 0.92 (0.02) [20]. Change in WS over time was more pronounced for fast $(-1.94 \mathrm{~cm} / \mathrm{s} /$ year $)$ than usual $(-0.71$ $\mathrm{cm} / \mathrm{s} /$ year) speed $[23,24]$. Random slope variability was higher for fast $(2.47, \mathrm{SE}=0.24)$ than usual (1.11, SE=0.13) WS. Given greater decline and inter-individual variability, we used fast WS as the main outcome in the analyses; we undertook sensitivity analyses for usual WS. In the remainder of the paper, WS refers to fast WS. 


\section{Disability}

Three domains of disability were assessed six times (baseline, waves 1, 2, 4, 5, 6). Mobility was assessed with the French translation of the Rosow and Breslau scale (ability to do heavy work around the house, walk half a mile, climb stairs) [25]. The Lawton-Brody instrumental activities of daily living (IADL) scale (French version) evaluated the ability to use a telephone, manage drugs and money, use public or private transport, and do shopping and, for women, to prepare meals and do housework and laundry [26]. Basic activities of daily living (ADL) were assessed through the Katz scale (need help with bathing, dressing, toileting, transferring from bed to chair, eating; French version); we excluded incontinence as it reflects organ impairment rather than functional limitation [27]. For each domain, participants were disabled if they could not perform $\geq 1$ activity without a given level of help.

We constructed a hierarchical disability indicator, which defines four levels of increasing disability by summing responses to the three dichotomized disability items in a hierarchy $(0=$ fully independent; $1=$ dependent only in relation to the Rosow scale; 2=dependent on the Rosow scale and IADLs but not ADLs; 3=dependent in all domains) [28]. As few persons were disabled in all domains, we compared those in groups $2 / 3$ (moderate/severe) with those in groups 0/1 (no/light disability).

\section{Statistical analysis}

At each wave, we excluded participants $>85$ years and those with conditions causing gait impairment (Parkinson's disease, dementia, hip fracture in the previous two years, disabling stroke) or with missing data for covariates (height, education, marital status).

Baseline BMI $\left(\mathrm{kg} / \mathrm{m}^{2}\right)$ was coded as a four-level variable (WHO classification): underweight $(<18.5)$, normal weight $(18.5-24.9)$, overweight $(25.0-29.9)$, obese $(\geq 30)$. As few participants $(<2 \%)$ were underweight, we combined them with the normal group as excluding 
them did not affect our findings. The cross-sectional BMI-WS association at baseline was examined using linear regression and that with disability using logistic regression. Model 1 was adjusted for confounders, including age, sex, height (correlation coefficient with $\mathrm{BMI}=0.01, \mathrm{p}=0.41$ ), and for WS, education as well. Model 2 was further adjusted for MMSE, depressive symptoms, bone fractures (other than hip), falls, physical activity, diabetes, dyspnea, NSAIDs use, knee/hip replacement for osteoarthritis, psychotropic drugs use, cardiovascular disease, hypertension, and hypercholesterolemia.

Inspection of spaghetti plots of BMI trajectories over time $(n=4,931)$ showed them to be linear, allowing us to model individual BMI trajectories over time using a linear mixed model. Time was modelled in years, divided by 10 , so that regression coefficients represent change in the outcome variable for an increase of 10 years. The model also contained baseline age, sex, and their interactions with time. A dummy variable 'self-reported $v s$. measured BMI' was added to account for error in self-reported BMI. The intercept and slope (time) were treated as random effects. Each individual's baseline BMI was estimated as the sum of the fixed effects for the intercept and covariates and of the random intercept using best linear unbiased prediction (BLUPs), individual 10-year slopes of change in BMI were estimated in a similar way [29]. BMI was categorized as normal weight, overweight, and obese, and change in BMI categorized based on its mean change $\left(0.38 \mathrm{~kg} / \mathrm{m}^{2} / 10\right.$ years $)$ and standard deviation ( $\mathrm{SD}=1.47)$ : 'decreasing' BMI for slopes <-1.09 (mean-one SD); 'increasing' BMI for slopes $\geq 1.85$ (mean+one SD); 'normal change' otherwise.

The association of BMI and change in BMI with change in WS was examined using a linear mixed model with intercept and slope (time) as random effects; using age as the time scale led to the same conclusions. A visual inspection of the data showed that WS trajectories over time were linear, and we included the following terms in the model: intercept, baseline BMI, time (in years, divided by 10), timexbaseline BMI, timexchange in BMI, baseline 
BMIxchange in BMIxtime. This model allows the estimation of change in WS for the nine groups defined by the cross-tabulation of baseline BMI and BMI change. Because the 3-way baseline BMIxchange in BMIxtime interaction was not significant, we ran a simpler model without this term, assuming that the association between change in BMI and change in WS did not depend on baseline BMI. In addition to baseline BMI, change in BMI, and covariates included in the cross-sectional analyses (age, sex, height, education) and, we examined all 2way interaction terms between these variables, and we retained in the final model interactions that were statistically significant $(\mathrm{p} \leq 0.05)$ : baseline $\mathrm{BMI} \times$ time, change in BMI $\times$ time, baseline BMI $\times$ sex, age $\times$ height, timexage, time $\times$ height. In sensitivity analyses, we examined the influence of missing WS through joint models, which jointly estimate the parameters of a linear mixed model and a survival model for time to drop-out. This approach allows the correction of longitudinal estimates by taking drop-out into account (supplementary methods). Because weight loss precedes death and dementia [30,31], we ran sensitivity analyses in order to assess whether they explained the association between BMI and decline in WS by excluding participants who developed dementia or died during the follow-up.

The association of BMI with disability over the follow-up was examined using a logistic mixed model with intercept and slope (time) as random effects with the following terms: intercept, baseline BMI, time (in years, divided by 10), timexbaseline BMI, timexchange in BMI. The 3-way baseline BMIxchange in BMIxtime interaction was not statistically significant and not included. Models 1 and 2 included the same covariates as above, as well as marital status and 2-way significant interactions: sex $\times$ age, sex $\times$ marital status, timexage, timexheight.

Analyses were performed with SAS 9.3 (SAS Institute Inc, Cary, North Carolina). $P$-values are 2 -sided and those $\leq 0.05$ considered statistically significant. 


\section{RESULTS}

After excluding participants aged $>85$ years at baseline $(n=239)$, with conditions causing gait impairment ( $\mathrm{n}=171)$, with missing data (height, education, marital status, $\mathrm{n}=18), 4,503$ participants were eligible. Among them 496 did not have any WS measure over the follow-up; they were older (77.4 vs. 73.4years, $P<0.001)$ and had higher baseline BMI (26.3 vs. $25.7 \mathrm{~kg} / \mathrm{m}^{2}$, age-adjusted $P<0.001$ ) than participants with at least one WS measure. Of the 4,007 participants in the analysis, 664 (16.6\%) had five WS measures, 575 (14.3\%) four, 568 $(14.2 \%)$ three, $898(22.4 \%)$ two, and 1,302 (32.5\%) a single measure. Table 1 presents participants' baseline characteristics: $14 \%$ of the participants were obese, baseline mean WS was $153 \mathrm{~cm} / \mathrm{s}(\mathrm{SD}=31)$. Older, less educated, divorced/separated/widowed, shorter, obese participants, women, and those in worse health walked slower.

Of 4,503 participants eligible for disability analyses, 25 had missing data for disability at all waves. Analyses are based on 4,478 subjects; $1,091(24 \%)$ reported disability at least once over the follow-up, and were older, less likely to be men, less educated, more likely to be divorced/separated/widowed, shorter, obese, and were in worse health than participants without disability (Supplementary Table 1).

Table 2 shows cross-sectional associations between BMI and WS (upper panel) and disability (lower panel). Overweight and obesity were associated with slower WS. Obesity but not overweight was associated with disability in model 1; this association was attenuated in the fully adjusted model.

Supplementary Table 2 shows the results of the linear mixed model; BMI increased over time, more slowly in men and older participants. $13 \%$ of participants were in the decreasing BMI group (mean change: $-2.07 \mathrm{~kg} / \mathrm{m}^{2} / 10$ years, $\mathrm{SD}=1.02$ ), $12 \%$ in the increasing group (mean change: $2.90 \mathrm{~kg} / \mathrm{m}^{2} / 10 y e a r s, \mathrm{SD}=1.05$ ), and $75 \%$ in the normal change category (mean change: $0.39 \mathrm{~kg} / \mathrm{m}^{2} / 10 y e a r s, \mathrm{SD}=0.71$ ). Baseline characteristics of these three groups 
are presented in Supplementary Table 3. Participants in the decreasing BMI group were oldest (sex-adjusted $\mathrm{P}<0.001$ ), those in the increasing and decreasing $\mathrm{BMI}$ groups were more likely to be women (age-adjusted $\mathrm{P}<0.001$ ) and divorced, separated or widowed (age- and sexadjusted $\mathrm{P}<0.001)$. Finally, participants in the decreasing BMI group were heavier at baseline compared to those in the other two groups (26.9 vs. 26.2 and 25.4, age- and sex-adjusted $\mathrm{P}<0.001)$.

Ten-year WS change was estimated for nine groups defined by the cross-tabulation of baseline BMI and BMI change (Supplementary Table 4). Independently of BMI change, WS decline was more pronounced in obese participants compared to the normal BMI group. Independently of baseline BMI, WS decline was less pronounced in the normal change group compared to the decreasing and increasing groups. However, the association between change in BMI and change in WS did not depend on baseline BMI as the p-value for the 3-way baseline BMIxchange in BMIxtime interaction was 0.69. Table 3 (upper panel) shows the results from a simpler model without this 3-way interaction term, assuming that both baseline BMI and change in BMI are independently associated with WS. This model suggests that obese participants at baseline, but not those overweight, had $45 \%(P=0.002)$ faster WS decline compared with normal weight participants. When compared to overweight, obesity was associated with faster decline (difference $=-4.06 \mathrm{~cm} / \mathrm{s} / 10 y e a r s, 95 \%$ Confidence Interval (CI), -7.67,-0.45, $P=0.03)$. Participants who lost or gained weight had $47 \%(P<0.001)$ and $33 \%(P=0.002)$ greater WS decline respectively than participants in the normal change category (Figure 1, panel A). Further adjustment for covariates (model 2) did not modify associations.

Analyses based on a joint model taking missing WS values into account yielded results consistent with our main analysis (Supplementary Tables 5). Analyses excluding participants who developed dementia or died over time (Supplementary Table 6) showed that 
most associations examined in the study were accentuated, except for the association between decreasing BMI over time and decline in WS which was attenuated but remained statistically significant. Analyses based on usual WS (Supplementary Tables 7) led to the same conclusions as for fast WS.

Table 3 (lower panel) shows longitudinal associations with disability. Obese persons had a higher risk of becoming disabled, although associations were not statistically significant. Compared to participants in the normal change category, those who lost or gained weight had a higher disability risk; the latter association became non-significant in model 2 . 


\section{DISCUSSION}

Our analyses of the relationship between BMI and motor decline in older adults yielded several findings: $(i)$ overweight and obese people walked slower at baseline than normal weight persons; the obese were more often disabled; (ii) WS decline was more pronounced in obese participants compared to others; (iii) independently of baseline BMI, persons in whom weight loss or gain was more pronounced experienced faster WS decline and more disability than others.

Our findings extend those from previous studies showing worse motor performance in obese persons, when BMI and motor function were measured simultaneously [32] or when BMI was assessed prior to motor function $[10,11]$. Longitudinal studies in this domain are rarer. One study showed no influence of baseline weight on motor decline [12], this study had a shorter follow-up ( 6y) with fewer mobility assessments (three) than ours. Another study examined the association between 2-year change in weight and subsequent lower body ADL limitations and onset of objectively assessed walking limitations over 5 years [14]. Weight loss was associated with greater risk of lower body ADL and walking limitations; weight gain was also associated with an increased risk of lower body ADL and walking limitations, although the latter association was not statistically significant. Another study showed that higher baseline weight was associated with greater WS decline over 10 years in women $\geq 65$ years but weight loss was not associated with WS decline [15]. Our findings are in line with studies showing high BMI and weight loss [6-8, 33] or gain [7] to be associated with greater risk of self-reported outcomes such as disability and mobility impairment.

The main contribution of our study is that obese persons had a more pronounced WS decline compared to normal weight persons. Obesity is associated with an inflammatory state through production of cytokines by adipose tissue [34], and inflammation has been shown to be associated with worse physical performance [35]. Obesity is associated with a range of 
adverse outcomes (e.g., hypertension, diabetes, cardiovascular disease, osteoarthritis) that affect motor function [36, 37]. Accordingly, the association between obesity and WS decline was attenuated after adjustment for comorbidities; dyspnea, knee/hip replacement for osteoarthritis, and diabetes played the stronger role. However, even after adjustment for a wide range of covariates, differences remained large and statistically significant. Obesity has a 'mechanical' effect on walking ability; obese persons are slowed down because they need to mobilize more weight. Biomechanical studies show that obese persons take shorter/wider strides, spend more time in the stance rather than the swing phase of the walking cycle, and are more erect throughout the stance phase than non-obese people, and therefore walk slower [38-40]. Adding mass to lean persons has been shown to lead to a deterioration of balance [41].

Regarding overweight, the difference in baseline WS with normal weight persons was less pronounced than for obese persons, overweight persons had a more pronounced decline compared to those with normal BMI but the difference was not statistically significant. The risk of disability was not greater in overweight persons, possibly because overweight has a weaker health impact than obesity in older persons [42].

Increasing BMI over the follow-up was associated with faster WS decline and an increased risk of disability. However, we cannot infer the causal direction of this association and there are two possible concurrent explanations. Weight gain may have adverse effects on mobility: as older people gain weight, they will have more difficulties in walking and performing daily activities. Alternatively, people who become disabled and have more trouble walking may gain weight as they become less active.

Weight loss over the follow-up was associated with WS decline and disability. Motor decline and weight loss are two important components of frailty [43], and it is likely that this association results from some participants becoming frail over the follow-up. A limitation of 
this study is that all the components of the frailty syndrome, such as grip strength, were not assessed in the study so we could not identify frailty cases in the study. However, obesity/overweight and weight gain rather than frailty were the main focus of our paper. Weight loss can also result from some chronic conditions. In our analyses, associations between decreasing BMI and WS decline/disability were attenuated after adjustment for comorbidities, particularly depressive symptoms, diabetes, and poor cognition. Weight loss is associated with dementia [31, 44], which is characterized by poorer motor performance [45]. Weight loss also precedes death [6, 46-49] but these mechanisms did not fully explain our findings as analyses excluding subjects who developed dementia or died yielded similar findings.

Our findings need to be considered in light of some limitations. First, WS was not measured at each wave for all participants. We used various approaches (analyses of selfreported disability measures available for most participants, a statistical method to take missing values into account) to assess the robustness of our findings and reached similar conclusions. Second, we could not determine whether weight loss was intentional. However, we found an association between weight loss and WS decline in those with normal baseline weight, in whom weight loss is unlikely to be intentional. In addition, there is evidence that those who lose weight intentionally are not at higher risk of disability $[8,50]$. Finally, only $2 \%(\mathrm{~N}=80)$ of participants were underweight at baseline, not allowing us to analyze this group separately. Underweight persons were less likely to be men than normal weight participants but after adjusting for sex, their walking speeds were similar $(\mathrm{P}=0.65)$. It is likely that underweight participants who agreed to participate in the study were in good health. The small sample size of this group did not allow us to examine decline in WS with sufficient statistical power, instead we repeated the analyses by excluding these participants and found it to have a negligible impact on our findings. 
This study's main strengths include its large size and long follow-up with up to five WS, and six disability and BMI measures. The main outcome is an objective reproducible measure of motor performance, with findings that were largely similar using self-reported outcomes.

In conclusion, our study suggests that obesity is associated with worse motor performance, a higher disability risk, and faster motor decline. Given demographic changes, the current trends of increasing BMI and obesity may have important consequences for disability-free life-expectancy $[51,52]$. Weight loss recommendations in older adults remain controversial [53]. Intentional weight loss (between 7-10\% of initial weight) in older overweight/obese persons through a combination of exercise and nutritional intervention is associated with improvement in WS [54]. Our results underline the interest of repeated BMI and motor assessments in older persons to identify those at higher risk of experiencing decline in WS or disability [43]. 
Acknowledgments: The 3C study was supported by a partnership agreement between the Institut National de la Santé et de la Recherche Médicale (INSERM), the Victor SegalenBordeaux II University, and the Sanofi-Synthélabo Company. The Fondation pour la Recherche Médicale funded the preparation and initiation of the study. The 3C study is also supported by the Caisse Nationale Maladie des Travailleurs Salariés, Direction Générale de la Santé, Conseils Régionaux of Bourgogne, Fondation de France, Ministry of Research-

INSERM Program, "Cohortes et collections de données biologiques”, Mutuelle Générale de l'Education Nationale, Institut de la Longévité, Conseil Général de la Côte d'or, Fondation Plan Alzheimer. Fanny Artaud is the recipient of a doctoral grant from the EHESP (Ecole des Hautes Etudes en Santé Publique), Rennes, France.

ASM receives research support from the US National Institutes of Health (R01AG013196, R01AG0344540).

Conflict of interest: The authors declare that they have no conflict of interest. 


\section{Figure legend}

Fig. 1 Predicted walking speed trajectories according to estimated baseline BMI and change in BMI in the 3C-Dijon study

Solid line, normal change in BMI; long-dashed line, decreasing BMI; short-dashed line, increasing BMI.

The intercept corresponds to the average walking speed for women aged 65 years at baseline, with low education, and a height of $162 \mathrm{~cm}$. The estimates are derived from a mixed linear model adjusted for these covariates, and including sex $\times$ baseline BMI, age $\times$ height, time $\times$ age, and time $\times$ height interaction terms. 


\section{REFERENCES}

1. Alexander NB, Goldberg A. Gait disorders: search for multiple causes. Cleve Clin J Med. 2005; 72(7): 586, 589-4

2. Cooper R, Kuh D, Cooper C, et al. Objective measures of physical capability and subsequent health: a systematic review. Age Ageing. 2011; 40(1): 14-23

3. Studenski S, Perera S, Patel K, et al. Gait speed and survival in older adults. JAMA. 2011; 305(1): 50-8

4. Finucane MM, Stevens GA, Cowan MJ, et al. National, regional, and global trends in body-mass index since 1980: systematic analysis of health examination surveys and epidemiological studies with 960 country-years and 9.1 million participants. Lancet. 2011; 377(9765): 557-67

5. Une enquête INSERM / Kantar Health / Roche. ObEpi 2012, Enquête épidémiologique nationale sur le surpoids et l'obésité. 2012.

6. Arnold AM, Newman AB, Cushman M, et al. Body weight dynamics and their association with physical function and mortality in older adults: the Cardiovascular Health Study. J Gerontol A Biol Sci Med Sci. 2010; 65(1): 63-70

7. Jensen GL, Friedmann JM. Obesity is associated with functional decline in community-dwelling rural older persons. J Am Geriatr Soc. 2002; 50(5): 918-23

8. Lee JS, Kritchevsky SB, Tylavsky F, et al. Weight change, weight change intention, and the incidence of mobility limitation in well-functioning community-dwelling older adults. $\mathbf{J}$ Gerontol A Biol Sci Med Sci. 2005; 60(8): 1007-12

9. Schaap LA, Koster A, Visser M. Adiposity, Muscle Mass, and Muscle Strength in Relation to Functional Decline in Older Persons. Epidemiol Rev. 2013; (35): 51-65

10. Houston DK, Ding J, Nicklas BJ, et al. The association between weight history and physical performance in the Health, Aging and Body Composition study. Int J Obes (Lond). 2007; 31(11): $1680-7$

11. Lang IA, Llewellyn DJ, Alexander K, et al. Obesity, physical function, and mortality in older adults. J Am Geriatr Soc. 2008; 56(8): 1474-8 
12. Mendes de Leon CF, Hansberry MR, Bienias JL, et al. Relative weight and mobility: a longitudinal study in a biracial population of older adults. Ann Epidemiol. 2006; 16(10): 770-6

13. Ortega-Alonso A, Sipila S, Kujala UM, et al. Genetic influences on adult body mass index followed over 29 years and their effects on late-life mobility: a study of twin sisters. J Epidemiol Community Health. 2009; 63(8): 651-8

14. Al Snih S, Raji MA, Markides KS, et al. Weight change and lower body disability in older Mexican Americans. J Am Geriatr Soc. 2005; 53(10): 1730-7

15. Forrest KY, Zmuda JM, Cauley JA. Correlates of decline in lower extremity performance in older women: A 10-year follow-up study. J Gerontol A Biol Sci Med Sci. 2006; 61(11): 1194200

16. Beavers KM, Beavers DP, Houston DK, et al. Associations between body composition and gaitspeed decline: results from the Health, Aging, and Body Composition study. Am J Clin Nutr. 2013; 97(3): 552-60

17. The $3 \mathrm{C}$ study Group. Vascular factors and risk of dementia: design of the Three-City Study and baseline characteristics of the study population. Neuroepidemiology. 2003; 22(6): 316-25

18. Villareal DT, Apovian CM, Kushner RF, et al. Obesity in older adults: technical review and position statement of the American Society for Nutrition and NAASO, The Obesity Society. Am J Clin Nutr. 2005; 82(5): 923-34

19. Hirani V. Generalised and abdominal adiposity are important risk factors for chronic disease in older people: results from a nationally representative survey. J Nutr Health Aging. 2011; 15(6): 469-78

20. Dumurgier J, Elbaz A, Dufouil C, et al. Hypertension and lower walking speed in the elderly: the Three-City study. J Hypertens. 2010; 28(7): 1506-14

21. Ling SM, Xue QL, Simonsick EM, et al. Transitions to mobility difficulty associated with lower extremity osteoarthritis in high functioning older women: longitudinal data from the Women's Health and Aging Study II. Arthritis Rheum. 2006; 55(2): 256-63

22. Peres K, Verret C, Alioum A, et al. The disablement process: factors associated with progression of disability and recovery in French elderly people. Disabil Rehabil. 2005; 27(5): 263-76 
23. Bohannon RW. Comfortable and maximum walking speed of adults aged 20-79 years: reference values and determinants. Age Ageing. 1997; 26(1): 15-9

24. Ko SU, Stenholm S, Metter EJ, et al. Age-associated gait patterns and the role of lower extremity strength - results from the Baltimore Longitudinal Study of Aging. Arch Gerontol Geriatr. 2012; 55(2): 474-9

25. Rosow I, Breslau N. A Guttman health scale for the aged. J Gerontol. 1966; 21(4): 556-9

26. Lawton MP, Brody EM. Assessment of older people: self-maintaining and instrumental activities of daily living. Gerontologist. 1969; 9(3): 179-86

27. Katz S, Ford AB, Moskowitz RW, et al. Studies of illness in the aged. The index of ADL: a standardized measure of biological and psychological function. JAMA. 1963; 185: 914-9

28. Barberger-Gateau P, Rainville C, Letenneur L, et al. A hierarchical model of domains of disablement in the elderly: a longitudinal approach. Disabil Rehabil. 2000; 22(7): 308-17

29. Rabe-Hesketh S, Skrondal A. Multilevel and Longitudinal Modeling Using Stata. 2nd ed. Texas: Stata Press; 2005

30. Alley DE, Metter EJ, Griswold ME, et al. Changes in weight at the end of life: characterizing weight loss by time to death in a cohort study of older men. Am J Epidemiol. 2010; 172(5): 55865

31. Knopman DS, Edland SD, Cha RH, et al. Incident dementia in women is preceded by weight loss by at least a decade. Neurology. 2007; 69(8): 739-46

32. Hardy R, Cooper R, Aihie SA, et al. Body mass index, muscle strength and physical performance in older adults from eight cohort studies: the HALCyon programme. PLoS One. 2013; 8(2): e56483.

33. Launer LJ, Harris T, Rumpel C, et al. Body mass index, weight change, and risk of mobility disability in middle-aged and older women. The epidemiologic follow-up study of NHANES I. JAMA. 1994; 271(14): 1093-8

34. Rodriguez-Hernandez H, Simental-Mendia LE, Rodriguez-Ramirez G, et al. Obesity and inflammation: epidemiology, risk factors, and markers of inflammation. Int J Endocrinol. 2013; 2013: 678159. 
35. Cesari M, Penninx BW, Pahor M, et al. Inflammatory markers and physical performance in older persons: the InCHIANTI study. J Gerontol A Biol Sci Med Sci. 2004; 59(3): 242-8

36. Felson DT, Anderson JJ, Naimark A, et al. Obesity and knee osteoarthritis. The Framingham Study. Ann Intern Med. 1988; 109(1): 18-24

37. Field AE, Coakley EH, Must A, et al. Impact of overweight on the risk of developing common chronic diseases during a 10-year period. Arch Intern Med. 2001; 161(13): 1581-6

38. Browning RC, Kram R. Effects of obesity on the biomechanics of walking at different speeds. Med Sci Sports Exerc. 2007; 39(9): 1632-41

39. DeVita P, Hortobagyi T. Obesity is not associated with increased knee joint torque and power during level walking. J Biomech. 2003; 36(9): 1355-62

40. Spyropoulos P, Pisciotta JC, Pavlou KN, et al. Biomechanical gait analysis in obese men. Arch Phys Med Rehabil. 1991; 72(13): 1065-70

41. Ledin T, Odkvist LM. Effects of increased inertial load in dynamic and randomized perturbed posturography. Acta Otolaryngol. 1993; 113(3): 249-52

42. Flegal KM, Kit BK, Orpana H, et al. Association of all-cause mortality with overweight and obesity using standard body mass index categories: a systematic review and meta-analysis. JAMA. 2013; 309(1): 71-82

43. Fried LP, Tangen CM, Walston J, et al. Frailty in older adults: evidence for a phenotype. J Gerontol A Biol Sci Med Sci. 2001; 56(3): M146-M156.

44. Buchman AS, Wilson RS, Bienias JL, et al. Change in body mass index and risk of incident Alzheimer disease. Neurology. 2005; 65(6): 892-7

45. Mielke MM, Roberts RO, Savica R, et al. Assessing the temporal relationship between cognition and gait: slow gait predicts cognitive decline in the mayo clinic study of aging. J Gerontol A Biol Sci Med Sci. 2013; 68(8): 929-37

46. Corrada MM, Kawas CH, Mozaffar F, et al. Association of body mass index and weight change with all-cause mortality in the elderly. Am J Epidemiol. 2006; 163(10): 938-49

47. Iribarren C, Sharp DS, Burchfiel CM, et al. Association of weight loss and weight fluctuation with mortality among Japanese American men. N Engl J Med. 1995; 333(11): 686-92 
48. Locher JL, Roth DL, Ritchie CS, et al. Body mass index, weight loss, and mortality in community-dwelling older adults. J Gerontol A Biol Sci Med Sci. 2007; 62(12): 1389-92

49. Newman AB, Yanez D, Harris T, et al. Weight change in old age and its association with mortality. J Am Geriatr Soc. 2001; 49(10): 1309-18

50. Ritchie CS, Locher JL, Roth DL, et al. Unintentional weight loss predicts decline in activities of daily living function and life-space mobility over 4 years among community-dwelling older adults. J Gerontol A Biol Sci Med Sci. 2008; 63(1): 67-75

51. Reynolds SL, Saito Y, Crimmins EM. The impact of obesity on active life expectancy in older American men and women. Gerontologist. 2005; 45(4): 438-44

52. Walter S, Kunst A, Mackenbach J, et al. Mortality and disability: the effect of overweight and obesity. Int J Obes (Lond). 2009; 33(12): 1410-8

53. Miller SL, Wolfe RR. The danger of weight loss in the elderly. J Nutr Health Aging. 2008; 12(7): 487-91

54. Beavers KM, Miller ME, Rejeski WJ, et al. Fat mass loss predicts gain in physical function with intentional weight loss in older adults. J Gerontol A Biol Sci Med Sci. 2013; 68(1): 80-6 
Table 1 Baseline characteristics of participants and associations with baseline walking speed in the 3C-Dijon study

\begin{tabular}{|c|c|c|c|c|c|}
\hline \multicolumn{3}{|c|}{ Characteristics } & \multirow{2}{*}{ Mean (SD) } & \multirow{3}{*}{$\begin{array}{c}\text { No. }(\%) \\
4,007\end{array}$} & \multirow{2}{*}{$\begin{array}{c}\begin{array}{c}\text { Baseline mean } \\
\text { fast } \mathbf{W S}^{\mathbf{a}}\end{array} \\
(\mathbf{c m} / \mathbf{s})(\mathbf{S D}) \\
153.1(30.7)\end{array}$} \\
\hline No. & & & & & \\
\hline \multirow[t]{5}{*}{ Age (years) } & & & $73.4(4.6)$ & & \\
\hline & $<70$ & & & $1,160(28.9)$ & $164.7(29.2)$ \\
\hline & {$[70-74[$} & & & $1,117(27.9)$ & $154.8(28.9)$ \\
\hline & {$[74-78[$} & & & $1,048(26.2)$ & $147.7(30.0)$ \\
\hline & $\geq 78$ & & & $682(17.0)$ & $139.3(29.6)$ \\
\hline \multirow[t]{2}{*}{ Sex } & Men & & & $1,539(38.4)$ & $167.9(30.4)$ \\
\hline & Women & & & $2,468(61.6)$ & $143.8(27.2)$ \\
\hline \multirow[t]{3}{*}{ Education } & No educatior & or primary school & & $1,388(34.6)$ & $144.8(28.6)$ \\
\hline & Secondary sc & hool & & $1,285(32.1)$ & $151.3(30.3)$ \\
\hline & High-school & or university degree & & $1,334(33.3)$ & $163.3(30.5)$ \\
\hline \multirow[t]{3}{*}{ Marital status } & Married & & & $2,391(59.7)$ & $157.7(30.2)$ \\
\hline & Divorced, se & arated or widowed & & $1,280(31.9)$ & $145.3(39.8)$ \\
\hline & Single & & & $336(8.4)$ & $149.0(31.9)$ \\
\hline \multirow[t]{5}{*}{ Height $(\mathrm{cm})$} & Men & Women & $161.8(8.8)$ & & \\
\hline & $<165$ & $<153$ & & $893(22.3)$ & $145.7(30.4)$ \\
\hline & {$[165 ; 170[$} & {$[153 ; 157[$} & & $1,030(25.7)$ & $151.1(29.4)$ \\
\hline & {$[170 ; 174[$} & {$[157 ; 161[$} & & $1,014(25.3)$ & $155.1(30.4)$ \\
\hline & $\geq 174$ & $\geq 161$ & & $1,070(26.7)$ & $159.3(31.1)$ \\
\hline \multirow[t]{4}{*}{ BMI $\left(\mathrm{kg} / \mathrm{m}^{2}\right)$} & & & $25.7(4.0)$ & & \\
\hline & Normal & & & $1,882(47.0)$ & $156.4(30.8)$ \\
\hline & Overweight & & & $1,583(39.5)$ & $153.2(30.1)$ \\
\hline & Obese & & & $542(13.5)$ & $141.0(29.5)$ \\
\hline \multirow[t]{4}{*}{ MMSE score } & & & $27.5(1.9)$ & & \\
\hline & $<27$ & & & $965(24.1)$ & $145.7(31.1)$ \\
\hline & {$[27 ; 28[$} & & & 704 (17.6) & $150.8(27.9)$ \\
\hline & $\geq 28$ & & & $2,338(58.3)$ & $156.8(30.7)$ \\
\hline \multirow[t]{2}{*}{ Depressive symptoms } & Yes & & & $891(22.3)$ & $141.4(28.9)$ \\
\hline & No & & & $3,111(77.7)$ & $156.4(30.4)$ \\
\hline \multirow[t]{2}{*}{ Bone fracture } & Yes & & & $273(6.8)$ & $145.1(30.0)$ \\
\hline & No & & & $3,734(93.2)$ & $153.6(30.7)$ \\
\hline \multirow[t]{2}{*}{ Falls } & Yes & & & $223(5.6)$ & $139.3(29.5)$ \\
\hline & No & & & $3,783(94.4)$ & $153.9(30.6)$ \\
\hline \multirow[t]{2}{*}{ Physical activity } & Low & & & $941(23.8)$ & $146.5(31.5)$ \\
\hline & High & & & $3,017(76.2)$ & $155.2(30.2)$ \\
\hline \multirow[t]{2}{*}{ Diabetes } & Yes & & & $299(7.5)$ & $150.2(31.9)$ \\
\hline & No & & & $3,708(92.5)$ & $153.3(30.6)$ \\
\hline
\end{tabular}




\begin{tabular}{|c|c|c|c|c|}
\hline & racteristics & Mean (SD) & No. $(\%)$ & $\begin{array}{c}\text { Baseline mean } \\
\text { fast } \mathbf{W S}^{\mathrm{a}}\end{array}$ \\
\hline Dyspnea & Yes & & $528(13.2)$ & $138.3(28.7)$ \\
\hline & No & & $3,479(86.8)$ & $155.4(30.4)$ \\
\hline NSAIDs for joint pain & Yes & & $604(15.1)$ & $141.9(30.4)$ \\
\hline & No & & $3,395(84.9)$ & $155.0(30.4)$ \\
\hline Knee/hip replacement & Yes & & $175(4.4)$ & $142.6(27.9)$ \\
\hline for osteoarthritis & No & & $3,832(95.6)$ & $153.5(30.8)$ \\
\hline Psychotropic drugs & Yes & & $1,000(25.0)$ & $142.4(29.1)$ \\
\hline & No & & $3,007(75.0)$ & $156.7(30.4)$ \\
\hline Cardiovascular disease $\mathrm{e}^{\mathrm{b}}$ & Yes & & $612(15.3)$ & $149.4(31.5)$ \\
\hline & No & & $3,395(84.7)$ & $153.7(30.6)$ \\
\hline Hypertension & Yes & & $3,164(79.0)$ & $151.8(30.9)$ \\
\hline & No & & $843(21.0)$ & $157.9(29.6)$ \\
\hline Hypercholesterolemia & Yes & & $1,340(33.4)$ & $151.1(29.0)$ \\
\hline & No & & $2,667(66.6)$ & $154.1(31.5)$ \\
\hline
\end{tabular}

Abbreviations: BMI: body mass index; MMSE, mini-mental state examination; NSAID, nonsteroidal anti-inflammatory drug; WS, walking speed.

${ }^{a}$ Based on 3,704 participants with a baseline walking speed measure.

${ }^{\mathrm{b}}$ Stroke, coronary heart disease, lower-limb arteritis. 
Table 2 Cross-sectional association of BMI with walking speed and disability in the 3C-Dijon study

\begin{tabular}{|c|c|c|c|c|c|c|}
\hline \multirow{2}{*}{$\begin{array}{l}\begin{array}{l}\text { Measure of } \\
\text { motor performances }\end{array} \\
\text { Walking speed }(\mathrm{cm} / \mathrm{s}) \\
\end{array}$} & \multicolumn{3}{|c|}{ Model $1 \mathrm{a}^{\mathrm{a}}(\mathrm{N}=3,704)$} & \multicolumn{3}{|c|}{ Model $2 \mathbf{a}^{b}(\mathbf{N}=3,644)$} \\
\hline & Beta $(95 \%$ CI $)$ & $\mathbf{P}$ & $\mathbf{P}^{\mathbf{c}}$ & Beta $(95 \%$ CI $)$ & $\mathbf{P}$ & $\mathbf{P}^{\mathbf{c}}$ \\
\hline Intercept $^{\mathrm{d}}$ & $161.34(158.91,163.78)$ & $<0.001$ & & $169.91(167.02,172.81)$ & $<0.001$ & \\
\hline \multicolumn{7}{|l|}{ Baseline BMI $\left(\mathrm{kg} / \mathrm{m}^{2}\right)$} \\
\hline Normal & Reference & & & Reference & & \\
\hline Overweight & $-6.31(-8.12,-4.50)$ & $<0.001$ & & $-4.83(-6.63,-3.04)$ & $<0.001$ & \\
\hline \multirow[t]{2}{*}{ Obese } & $-16.45(-19.02,-13.89)$ & $<0.001$ & $<0.001$ & $-12.94(-15.53,-10.34)$ & $<0.001$ & $<0.001$ \\
\hline & \multicolumn{3}{|c|}{ Model $1 b^{\mathrm{e}}(\mathrm{N}=4,345)$} & \multicolumn{3}{|c|}{ Model $2 b^{f}(N=4,143)$} \\
\hline Disability & OR $(95 \%$ CI $)$ & $\mathbf{P}$ & $\mathbf{P}^{\mathbf{c}}$ & OR $(95 \% \mathrm{CI})$ & $\mathbf{P}$ & $\mathbf{P}^{\mathbf{c}}$ \\
\hline \multicolumn{7}{|l|}{ Baseline BMI $\left(\mathrm{kg} / \mathrm{m}^{2}\right)$} \\
\hline Normal & Reference & & & Reference & & \\
\hline Overweight & $1.09(0.83,1.43)$ & 0.55 & & $1.02(0.75,1.39)$ & 0.89 & \\
\hline Obese & $1.75(1.24,2.46)$ & 0.001 & 0.005 & $1.18(0.79,1.76)$ & 0.43 & 0.48 \\
\hline
\end{tabular}

Abbreviations: BMI, body mass index; CI, confidence interval; OR, odds ratio.

${ }^{a}$ Model 1a: Adjusted for age at baseline (centered at 65y), sex (reference, women), education (reference, low education), height at baseline (centered at $162 \mathrm{~cm}$ ). These analyses are based on 3,704 participants.

${ }^{\mathrm{b}}$ Model 2a: Model 1a + MMSE, depressive symptoms, bone fractures, falls, physical activity, diabetes, dyspnea, regular use of NSAIDs for joint pain, hospitalization for osteoarthritis, use of psychotropic drugs, cardiovascular disease (stroke, coronary heart disease, lower-limb arteritis), hypertension, hypercholesterolemia. These analyses are based on 3,644 participants without missing covariates at baseline.

${ }^{\mathrm{c}} \mathrm{P}$ for trend.

${ }^{\mathrm{d}}$ The intercept (model 1a) corresponds to the average fast walking speed for women aged 65 years at baseline, with normal BMI, low education, and a height of $162 \mathrm{~cm}$. In model 2a, the intercept was calculated for the following values of the adjustment covariates: higher tertile of MMSE, no depressive symptoms, no history of fractures, no falls, high physical activity, no diabetes, no dyspnea, no use of NSAIDs, no hospitalization for osteoarthritis, no use of psychotropic drugs, no cardiovascular disease, no history of hypertension, no hypercholesterolemia.

${ }^{\mathrm{e}}$ Model 1b: Adjusted for age at baseline (centered at 65y), sex (reference, women), height at baseline (centered at $162 \mathrm{~cm}$ ). These analyses are based on 4,345 participants. 


\section{Table 2 (continued)}

${ }^{\mathrm{f}}$ Model 2b: Model 1b + MMSE, depressive symptoms, bone fractures, falls, physical activity, diabetes, dyspnea, regular use of NSAIDs for joint pain, hospitalization for osteoarthritis, use of psychotropic drugs, cardiovascular disease (stroke, coronary heart disease, lower-limb arteritis), hypertension, hypercholesterolemia. These analyses are based on 4,143 participants without missing covariates at baseline. 
Table 3 Longitudinal association of baseline BMI and change in BMI with walking speed and disability in the 3C-Dijon study

\begin{tabular}{|c|c|c|c|c|c|c|}
\hline \multirow{2}{*}{$\begin{array}{l}\begin{array}{l}\text { Measure of } \\
\text { motor performances }\end{array} \\
\text { Walking speed }(\mathrm{cm} / \mathrm{s})\end{array}$} & \multicolumn{3}{|c|}{ Model $1 \mathrm{a}^{\mathrm{a}}(\mathrm{N}=\mathbf{4 , 0 0 7})$} & \multicolumn{3}{|c|}{ Model $2 \mathrm{a}^{\mathrm{b}}(\mathrm{N}=3,923)$} \\
\hline & Beta $(95 \%$ CI $)$ & $\mathbf{P}$ & $\mathbf{P}$ & Beta $(95 \%$ CI) & $\mathbf{P}$ & $\mathbf{P}$ \\
\hline Change in WS over $10 \mathrm{y}$ & $-12.85(-15.33,-10.36)$ & $<0.001$ & & $-11.47(-13.93,-9.01)$ & $<0.001$ & \\
\hline \multicolumn{7}{|c|}{ Baseline $\mathrm{BMI} \times 10 \mathrm{y}$ change in $\mathrm{WS}$} \\
\hline Normal & Reference & & & Reference & & \\
\hline Overweight & $-1.72(-3.95,0.51)$ & 0.13 & & $-1.08(-3.28,1.13)$ & 0.34 & \\
\hline Obese & $-5.78(-9.36,-2.20)$ & 0.002 & $0.003^{\mathrm{c}}$ & $-4.21(-7.77,-0.66)$ & 0.02 & $0.04^{\mathrm{c}}$ \\
\hline \multicolumn{7}{|c|}{ Change in BMI $\times 10 y$ change in WS } \\
\hline Decreasing & $-6.00(-9.16,-2.85)$ & $<0.001$ & & $-5.99(-9.07,-2.91)$ & $<0.001$ & \\
\hline Normal & Reference & & & Reference & & \\
\hline \multirow[t]{2}{*}{ Increasing } & $-4.24(-6.87,-1.60)$ & 0.002 & $<0.001^{\mathrm{d}}$ & $-3.79(-6.37,-1.22)$ & 0.004 & $<0.001^{\mathrm{d}}$ \\
\hline & \multicolumn{3}{|c|}{ Model $1 b^{e}(N=4,478)$} & \multicolumn{3}{|c|}{ Model $2 b^{f}(N=4,270)$} \\
\hline Disability & OR $(95 \% \mathrm{CI})$ & $\mathbf{P}$ & $\mathbf{P}$ & OR $(95 \% \mathrm{CI})$ & $\mathbf{P}$ & $\mathbf{P}$ \\
\hline Time (per 10y) & $16.61(10.72,25.75)$ & $<0.001$ & & $13.98(8.79,21.22)$ & $<0.001$ & \\
\hline \multicolumn{7}{|c|}{ Baseline $\mathrm{BMI} \times 10 \mathrm{y}$ disability risk } \\
\hline Normal & Reference & & & Reference & & \\
\hline Overweight & $1.14(0.80,1.64)$ & 0.46 & & $1.14(0.78,1.66)$ & 0.51 & \\
\hline Obese & $1.47(0.92,2.36)$ & 0.11 & $0.28^{\mathrm{c}}$ & $1.48(0.90,2.45)$ & 0.12 & $0.30^{\mathrm{c}}$ \\
\hline \multicolumn{7}{|c|}{ Change in $\mathrm{BMI} \times 10 \mathrm{y}$ disability risk } \\
\hline Decreasing & $1.63(1.18,2.26)$ & 0.003 & & $1.48(1.06,2.05)$ & 0.02 & \\
\hline Normal & Reference & & & Reference & & \\
\hline Increasing & $1.34(1.00,1.79)$ & 0.05 & $0.001^{\mathrm{d}}$ & $1.20(0.90,1.61)$ & 0.22 & $0.02^{\mathrm{d}}$ \\
\hline
\end{tabular}

Abbreviations: BMI, body mass index; CI, confidence interval; OR, odds ratio.

${ }^{a}$ Model 1a: Linear mixed model adjusted for age at baseline (centered at 65y), sex (reference, women), education (reference, low education), height at baseline (centered at $162 \mathrm{~cm}$ ), estimated baseline BMI (reference, normal), age $\times$ height, sex $\times$ BMI, time $\times$ age, time $\times$ height. These analyses are based on 4,007 participants. 


\section{Table 3 (continued)}

${ }^{b}$ Model 2a: Model 1a + MMSE, depressive symptoms, bone fractures, falls, physical activity, diabetes, dyspnea, regular use of NSAIDs for joint pain, hospitalization for osteoarthritis, use of psychotropic drugs, cardiovascular disease (stroke, coronary heart disease, lower-limb arteritis), hypertension, hypercholesterolemia. These analyses are based on 3,923 participants without missing covariates.

${ }^{\mathrm{c}} \mathrm{P}$ for trend.

${ }^{\mathrm{d}} \mathrm{P}$ for quadratic effect (based on orthogonal polynomials).

${ }^{\mathrm{e}}$ Model 1b: Logistic mixed model adjusted for age at baseline (centered at 65y), sex (reference, women), marital status (reference, married), height at baseline (centered at $162 \mathrm{~cm}$ ), estimated baseline BMI (reference, normal), sex $\times$ age, sex $\times$ marital status, time $\times$ age, time $\times$ height. These analyses are based on 4,478 participants.

${ }^{\mathrm{f}}$ Model 2b: Model 1b + MMSE, depressive symptoms, bone fractures, falls, physical activity, diabetes, dyspnea, regular use of NSAIDs for joint pain, hospitalization for osteoarthritis, use of psychotropic drugs, cardiovascular disease (stroke, coronary heart disease, lower-limb arteritis), hypertension, hypercholesterolemia. These analyses are based on 4,270 participants without missing covariates. 

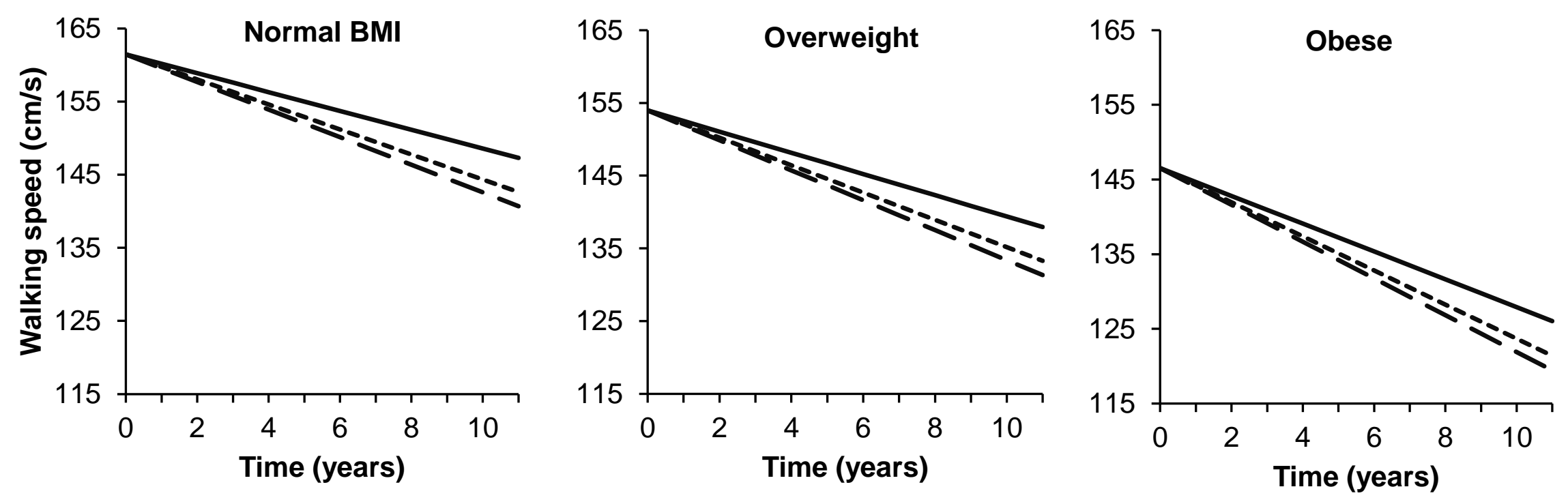


\section{Supplementary Methods}

\section{Covariates}

Baseline socio-demographic covariates included: age, sex, education (no education/primary school, secondary school, high-school/university degree), and marital status (married, divorced/separated/widowed, single).

The following covariates were assessed at baseline and at each wave of data collection. Cognition was assessed using the mini-mental state examination (MMSE), with higher scores corresponding to better function; MMSE was categorized in tertiles for the analyses. Depressive symptoms were evaluated with the Centre for Epidemiological StudiesDepression scale (CES-D) [1]; we used a cut-off of 16 to define the presence of depressive symptoms. History of bone fracture and falls was assessed over the two years previous to each visit. Low level of physical activity was defined as walking less than one hour per day and exercising less than once a week (assessed at baseline and waves 5 and 6; we used physical activity at baseline to impute values at waves 1 and 2, and physical activity at wave 5 to impute values at wave 4). History of knee or hip replacement for osteoarthritis, selfreported diabetes, dyspnea (New York Heart Association classification), regular use of nonsteroidal anti-inflammatory drug (NSAID) for joint pain, psychotropic drugs, cardiovascular disease (non-disabling stroke, coronary heart disease (CHD), lower-limb arteritis), hypertension (systolic blood pressure $\geq 140 \mathrm{~mm} \mathrm{Hg}$ or diastolic blood pressure $\geq 90 \mathrm{~mm} \mathrm{Hg}$ or antihypertensive medication), and lipid lowering drugs as a surrogate for hypercholesterolemia were assessed. Incident stroke and CHD events were validated by expert committees based on medical records [2]. Cardiovascular disease was defined by a positive history of stroke, CHD, or lower-limb arteritis.

The diagnosis of dementia at baseline and each follow-up examination was established according to a standardized 3-step procedure [3, 4]. First, trained neuropsychologists 
administered to all participants a battery of neuropsychological tests assessing memory, attention, language, and visuospatial abilities. Second, a neurologist examined all participants suspected of having dementia based on their neuropsychological evaluation (using age- and education-specific cut-offs for the MMSE, Benton Visual Retention Test, and Isaac Set Test). Third, a committee of expert neurologists reviewed all potential cases of dementia, and reached a consensus on diagnosis and classification based on standard criteria [5].

\section{Statistical analysis}

\section{Missing data}

Data on WS over the follow-up were missing due to death, participants reaching their 86th birthday, incident causes of gait impairment, home exams (where walking speed measures were not undertaken except at wave 6), and non-response. Linear mixed models assume that data over the follow-up are missing at random. Given the potential selection bias arising from higher mortality or drop-out in relation to BMI, the missing at random assumption might not hold. In order to investigate the influence of missing data, we used a joint modeling approach. This approach models change using a linear mixed model alongside a survival model for time to drop-out [6]; for these analyses, we considered that participants $\leq 85 \mathrm{y}$ old in whom WS was not measured (because they stopped coming to the study center, died, or developed a cause of marked gait impairment) dropped out. Of the 4,007 participants included in these analyses, $23 \%$ died, $6 \%$ developed a cause of marked gait impairment, and $31 \%$ dropped-out at some point during the follow-up. These participants were older, less educated, had a higher baseline BMI, were more likely to be in the normal change BMI category, and walked slower at baseline than participants who did not drop-out. The joint model links the two sub-models by including shared random effects that allows for dependency between the longitudinal process and time to drop-out. This approach allows to correct longitudinal estimates by taking drop- 
out into account. The survival model included covariates associated with the risk of drop-out including sex, age, and baseline BMI. This approach was implemented through the stjm command in Stata 12.1 (College Station, TX: StataCorp LP).

\section{Supplementary References}

1. Fuhrer R, Rouillon F. La version française de l'échelle CES-D (Center for Epidemiologic Studies-Depression Scale). Description et traduction de l'échelle d'autoévaluation. Psychiatrie et psychobiologie. 1989; 4: 163-6

2. Blachier M, Dauvilliers Y, Jaussent I, et al. Excessive daytime sleepiness and vascular events: the Three City Study. Ann Neurol. 2012; 71(5): 661-7

3. Raffaitin C, Gin H, Empana JP, et al. Metabolic syndrome and risk for incident Alzheimer's disease or vascular dementia: the Three-City Study. Diabetes Care. 2009; 32(1): $169-74$

4. The 3C study Group. Vascular factors and risk of dementia: design of the Three-City Study and baseline characteristics of the study population. Neuroepidemiology. 2003; 22(6): $316-25$

5. McKhann G, Drachman D, Folstein M, et al. Clinical diagnosis of Alzheimer's disease: report of the NINCDS-ADRDA Work Group under the auspices of Department of Health and Human Services Task Force on Alzheimer's Disease. Neurology. 1984; 34(7): 939-44

6. Henderson R, Diggle P, Dobson A. Joint modelling of longitudinal measurements and event time data. Biostatistics. 2000; 1(4): 465-80 
Supplementary Table 1. Characteristics of the Participants, Overall and According to Disability Status During the Follow-up in the 3C-Dijon Study

\begin{tabular}{|c|c|c|c|}
\hline Characteristics & Overall & Not disabled & $\begin{array}{c}\text { Disabled at least } \\
\text { once during the } \\
\text { follow-up }\end{array}$ \\
\hline \multicolumn{4}{|l|}{ Baseline covariates } \\
\hline No. $(\%)$ & 4,478 & $3,387(75.6)$ & $1,091(24.4)$ \\
\hline Mean (SD) age (years) & $73.8(4.8)$ & $73.5(4.8)$ & $74.7(4.8)$ \\
\hline Male Sex & $1,702(38.0)$ & $1,414(41.7)$ & $288(26.4)$ \\
\hline \multicolumn{4}{|l|}{ Education } \\
\hline No education or primary school & $1,559(34.8)$ & $1,131(33.4)$ & $428(39.2)$ \\
\hline Secondary school & $1,450(32.4)$ & $1,100(32.5)$ & $350(32.1)$ \\
\hline High-school or university degree & $1,469(32.8)$ & $1,156(34.1)$ & $313(28.7)$ \\
\hline \multicolumn{4}{|l|}{ Marital status } \\
\hline Married & $2,605(58.2)$ & $1,992(58.8)$ & $613(56.2)$ \\
\hline Divorced, separated, or widowed & $1,499(33.5)$ & $1,098(32.4)$ & $401(36.8)$ \\
\hline Single & $374(8.4)$ & $297(8.8)$ & $77(7.1)$ \\
\hline Mean $(\mathrm{SD})$ height $(\mathrm{cm})$ & $161.8(8.7)$ & $162.3(8.7)$ & $160.1(8.6)$ \\
\hline Mean $(\mathrm{SD}) \mathrm{BMI}\left(\mathrm{kg} / \mathrm{m}^{2}\right)$ & $25.8(3.9)$ & $25.6(3.7)$ & $26.5(4.5)$ \\
\hline Normal & $2,041(45.6)$ & $1,605(47.4)$ & $436(40.0)$ \\
\hline Overweight & $1,844(41.2)$ & $1,406(41.5)$ & $438(40.1)$ \\
\hline Obese & $593(13.2)$ & $376(11.1)$ & $217(19.9)$ \\
\hline \multicolumn{4}{|l|}{ Time dependent covariates } \\
\hline No. (\%) & 4,270 & $3,234(75.7)$ & $1,036(24.3)$ \\
\hline Mean (SD) MMSE score ${ }^{b}$ & $27.3(1.7)$ & $27.4(1.6)$ & $27.1(1.8)$ \\
\hline Depressive symptoms $^{c}$ & $1,700(39.8)$ & $1,113(34.4)$ & $587(56.7)$ \\
\hline Bone fracture $^{c}$ & $763(17.9)$ & $512(15.8)$ & $251(24.2)$ \\
\hline Falls $^{c}$ & $1,244(29.1)$ & $834(25.8)$ & $410(39.6)$ \\
\hline Low physical activity ${ }^{\mathrm{c}}$ & $1,657(38.8)$ & $1,071(33.1)$ & $586(56.6)$ \\
\hline Diabetes $^{c}$ & $555(13.0)$ & $396(12.2)$ & $159(15.3)$ \\
\hline Dyspnea $^{c}$ & $1,166(27.3)$ & $700(21.6)$ & $466(45.0)$ \\
\hline NSAIDs for joint pain ${ }^{c}$ & $968(22.7)$ & $632(19.5)$ & $336(32.4)$ \\
\hline Osteoarthritis $^{c}$ & $392(9.2)$ & $242(7.5)$ & $150(14.5)$ \\
\hline Psychotropic drugs ${ }^{c}$ & $1,822(42.7)$ & $1,254(38.8)$ & $568(54.8)$ \\
\hline Cardiovascular disease $^{c}$ & $948(22.2)$ & $685(21.2)$ & $263(25.4)$ \\
\hline Hypertension $^{\mathrm{c}}$ & $3,838(89.9)$ & $2,882(89.1)$ & $956(92.3)$ \\
\hline Hypercholesterolemia $^{c}$ & $1,973(46.2)$ & $1,495(46.2)$ & $478(46.1)$ \\
\hline
\end{tabular}

Abbreviations: MMSE, mini-mental state examination; NSAID, non-steroidal antiinflammatory drug.

Values are numbers (percentage) unless stated otherwise.

a $724(66.4 \%)$ were disabled once, $242(22.2 \%)$ twice, and $125(11.4 \%)$ three times or more.

${ }^{\mathrm{b}}$ Mean of all measures taken during follow-up.

${ }^{\mathrm{c}}$ At least one report over follow-up. 
Supplementary Table 2. Linear Mixed Model Estimates of Baseline BMI and Change in BMI Over the Follow-up in the 3C-Dijon Study $(n=4,931)$

\begin{tabular}{lcc}
\hline \multicolumn{1}{c}{ Characteristics } & Beta $(\mathbf{9 5 \%}$ CI) & P \\
\hline Intercept & $26.00(25.76,26.23)$ & $<0.001$ \\
Sex (men $v s$. women) & $0.79(0.56,1.02)$ & $<0.001$ \\
Age (centered at 65 years) & $-0.07(-0.09,-0.05)$ & $<0.001$ \\
Declared vs. measured BMI at each visit & $-0.19(-0.23,-0.16)$ & $<0.001$ \\
Time (change for 10 years) & $1.13(0.96,1.30)$ & $<0.001$ \\
Time $\times$ sex & $-0.15(-0.32,0.01)$ & 0.07 \\
Time $\times$ age & $-0.08(-0.10,-0.07)$ & $<0.001$ \\
\hline
\end{tabular}


Supplementary Table 3. Baseline characteristics of the Participants, Overall and According to Group of Change in BMI During the Follow-up in the 3C-Dijon Study $(n=4,007)$

\begin{tabular}{lcccc}
\hline \multicolumn{1}{c}{ Characteristics } & Overall & $\begin{array}{c}\text { Decreasing } \\
\text { group }\end{array}$ & $\begin{array}{c}\text { Normal } \\
\text { change group }\end{array}$ & $\begin{array}{c}\text { Increasing } \\
\text { group }\end{array}$ \\
\hline No. (\%) & 4,007 & $512(12.8)$ & $3,016(75.3)$ & $479(12)$ \\
Mean (SD) age (years) & $73.4(4.6)$ & $75.4(4.9)$ & $73.3(4.6)$ & $71.7(4.1)$ \\
Male Sex & $1,539(38.4)$ & $178(34.8)$ & $1,223(40.6)$ & $138(28.8)$ \\
Education & & & & \\
$\quad$ No education or primary school & $1,388(34.6)$ & $183(35.7)$ & $1,027(34.1)$ & $178(37.2)$ \\
$\quad$ Secondary school & $1,285(32.1)$ & $165(32.2)$ & $972(32.2)$ & $148(30.9)$ \\
$\quad$ High-school or university degree & $1,334(33.3)$ & $164(32)$ & $1,017(33.7)$ & $153(31.9)$ \\
Marital status & & & & \\
$\quad$ Married & $2,391(59.7)$ & $280(54.7)$ & $1,872(62.1)$ & $239(49.9)$ \\
$\quad$ Divorced, separated, or widowed & $1,280(31.9)$ & $174(34)$ & $899(29.8)$ & $207(43.2)$ \\
Single & $336(8.4)$ & $58(11.3)$ & $245(8.1)$ & $33(6.9)$ \\
Mean (SD) height $(\mathrm{cm})$ & $161.8(8.8)$ & $160.8(8.8)$ & $162.1(8.9)$ & $161.1(8.1)$ \\
Mean (SD) BMI $\left(\mathrm{kg} / \mathrm{m}^{2}\right)$ & $25.7(4.0)$ & $26.9(4.4)$ & $25.4(3.9)$ & $26.2(4.0)$ \\
$\quad$ Normal & $1882(47.0)$ & $198(38.7)$ & $1483(49.2)$ & $201(42.0)$ \\
$\quad$ Overweight & $1583(39.5)$ & $199(38.9)$ & $1177(39.0)$ & $207(43.2)$ \\
$\quad$ Obese & $542(13.5)$ & $115(22.5)$ & $356(11.8)$ & $71(14.8)$ \\
\hline
\end{tabular}


Supplementary Table 4. Estimates of Slope of Change in Fast Walking Speed According to Baseline BMI and Change in BMI in the 3C-Dijon Study $(n=4,007)$

\begin{tabular}{|c|c|c|c|}
\hline $\begin{array}{c}\text { Change in WS } \\
(\mathbf{9 5 \%} \mathbf{~ C I})\end{array}$ & \multicolumn{3}{|c|}{ Baseline BMI } \\
\hline Change in BMI & Normal & Overweight & Obese \\
\hline \multirow{2}{*}{ Decreasing } & $\mathrm{N}=203(5.1 \%)$ & $\mathrm{N}=215(5.4 \%)$ & $\mathrm{N}=94(2.3 \%)$ \\
& $-19.0(-23.9,-14.0)$ & $-21.5(-26.7,-16.3)$ & $-22.7(-30.1,-15.2)$ \\
\hline \multirow{2}{*}{ Normal change } & $\mathrm{N}=1,457(36.4 \%)$ & $\mathrm{N}=1,232(30.7 \%)$ & $\mathrm{N}=327(8.1 \%)$ \\
& $-12.7(-15.3,-10.2)$ & $-15.0(-17.7,-12.3)$ & $-18.4(-22.9,-14.0)$ \\
\hline \multirow{2}{*}{ Increasing } & $\mathrm{N}=177(4.4 \%)$ & $\mathrm{N}=219(5.5 \%)$ & $\mathrm{N}=83(2.1 \%)$ \\
& $-18.3(-22.7,-13.9)$ & $-17.3(-21.1,-13.5)$ & $-25.0(-31.4,-18.7)$ \\
\hline
\end{tabular}

${ }^{\mathrm{a}}$ Based on a linear mixed model adjusted for age at baseline (centered at $65 \mathrm{y}$ ), sex (reference, women), education (reference, low education), height at baseline (centered at $162 \mathrm{~cm}$ ), baseline BMI (reference, normal BMI), baseline BMI $\times$ sex, age $\times$ height, time $\times$ age, time $\times$ height, time $\times$ baseline BMI, time $\times$ change in BMI, time $\times$ baseline $\mathrm{BMI} \times$ change in BMI. 
Supplementary Table 5. Longitudinal Association of Baseline BMI and Change in BMI With Fast Walking Speed in the 3C-Dijon Study: Analyses Based on a Joint Model of WS and WS Missing Values $(n=4,007)$

\begin{tabular}{lcc}
\hline \multicolumn{1}{c}{ Characteristics } & Beta $(\mathbf{9 5 \%} \mathbf{C I})^{\mathbf{a}}$ & P \\
\hline Change in WS over 10y & $-13.19(-15.71,-10.67)$ & $<0.001$ \\
Baseline BMI $\times 10 \mathrm{y}$ change in WS & Reference & \\
$\quad$ Normal & $-1.87(-4.10,0.36)$ & 0.10 \\
Overweight & $-6.38(-9.97,-2.79)$ & $<0.001$ \\
Obese & $-5.96(-9.10,-2.81)$ & $<0.001$ \\
Change in BMI $\times$ 10y change in WS & Reference & \\
$\quad$ Decreasing & $-4.19(-6.83,-1.55)$ & 0.002 \\
$\quad$ Normal &
\end{tabular}

${ }^{\mathrm{a}}$ Model adjusted for age at baseline (centered at 65y), sex (reference, women), education (reference, low education), height at baseline (centered at $162 \mathrm{~cm}$ ), estimated baseline BMI (reference, normal), age $\times$ height, sex $\times$ BMI, time $\times$ age, time $\times$ height. 
Supplementary Table 6. Longitudinal Association of Baseline BMI and Change in BMI With Fast Walking Speed in the 3C-Dijon study: Analyses Based on Participants who did not Develop Dementia or did not die During the Follow-up $(n=2,915)$

\begin{tabular}{lccc}
\hline \multicolumn{1}{c}{ Characteristics } & Beta $(\mathbf{9 5 \%} \text { CI })^{\mathbf{a}}$ & $\mathbf{P}$ & $\mathbf{P}$ \\
\hline Change in WS over 10y & $-12.30(-14.85,-9.74)$ & $<0.001$ & \\
Baseline BMI $\times 10 y$ change in WS & Reference & & \\
$\quad$ Normal & $-2.37(-4.67,-0.08)$ & 0.04 & \\
$\quad$ Overweight & $-6.85(-10.60,-3.10)$ & $<0.001$ & $<0.001^{\text {b }}$ \\
$\quad$ Obese & $-4.55(-7.85,-1.24)$ & 0.01 & \\
Change in BMI $\times$ 10y change in WS & Reference & & \\
$\quad$ Decreasing & $-4.45(-7.12,-1.78)$ & 0.001 & $<0.001^{\mathrm{c}}$ \\
$\quad \begin{array}{l}\text { Normal } \\
\text { Increasing }\end{array}$
\end{tabular}

\footnotetext{
${ }^{\mathrm{a}}$ Model adjusted for age at baseline (centered at 65y), sex (reference, women), education (reference, low education), height at baseline (centered at $162 \mathrm{~cm}$ ), estimated baseline BMI (reference, normal), age $\times$ height, sex $\times$ BMI, time $\times$ age, time $\times$ height.

${ }^{\mathrm{b}} \mathrm{P}$ for trend.

${ }^{\mathrm{c}} \mathrm{P}$ for quadratic effect (based on orthogonal polynomials).
} 
Supplementary Table 7. Association of Baseline BMI and Change in BMI With Usual Walking Speed in the 3C-Dijon Study

\begin{tabular}{|c|c|c|c|}
\hline Characteristics & Beta $(95 \%$ CI) & $\mathbf{P}$ & $\mathbf{P}$ \\
\hline \multicolumn{4}{|c|}{ Baseline association $^{\mathrm{a}}(\mathrm{n}=3,779)$} \\
\hline Intercept & $118.45(116.74,120.16)$ & $<0.001$ & \\
\hline \multicolumn{4}{|l|}{ Baseline BMI $\left(\mathrm{kg} / \mathrm{m}^{2}\right)$} \\
\hline Normal & Reference & & \\
\hline Overweight & $-3.91(-5.18,-2.64)$ & $<0.001$ & \\
\hline Obese & $-11.06(-12.84,-9.28)$ & $<0.001$ & $<0.001^{\mathrm{b}}$ \\
\hline \multicolumn{4}{|c|}{ Longitudinal association $^{\mathrm{c}}(\mathrm{n}=4,060)$} \\
\hline Change in WS over $10 \mathrm{y}$ & $-3.20(-5.14,-1.26)$ & 0.001 & \\
\hline \multicolumn{4}{|c|}{ Baseline $\mathrm{BMI} \times 10 \mathrm{y}$ change in WS } \\
\hline Normal & Reference & & \\
\hline Overweight & $-2.85(-4.54,-1.15)$ & 0.001 & \\
\hline Obese & $-2.99(-5.66,-0.31)$ & 0.03 & $0.002^{\mathrm{b}}$ \\
\hline \multicolumn{4}{|c|}{ Change in $\mathrm{BMI} \times 10 \mathrm{y}$ change in $\mathrm{WS}$} \\
\hline Decreasing & $-4.23(-6.60,-1.85)$ & 0.001 & \\
\hline Normal & Reference & & \\
\hline Increasing & $-2.89(-4.85,-0.93)$ & 0.004 & $<0.001^{\mathrm{d}}$ \\
\hline
\end{tabular}

${ }^{\mathrm{a}}$ Model adjusted for age at baseline (centered at 65y), sex (reference, women), education (reference, low education), height at baseline (centered at $162 \mathrm{~cm}$ ). These analyses are based on 3,779 participants.

${ }^{\mathrm{b}} \mathrm{P}$ for trend.

${ }^{\mathrm{c}}$ Model adjusted for age at baseline (centered at 65y), sex (reference, women), education (reference, low education), height at baseline (centered at $162 \mathrm{~cm}$ ), time $\times$ age, time $\times$ sex, time $\times$ height. These analyses are based on 4,060 participants.

${ }^{\mathrm{d}} \mathrm{P}$ for quadratic effect (based on orthogonal polynomials). 